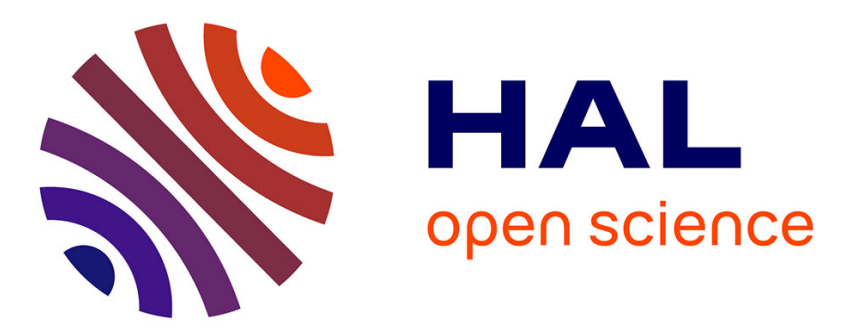

\title{
Architecting the CDIO Educational Framework Pursuant to Constructive Alignment Principles
}

Siegfried Rouvrais, Vanea Chiprianov

\section{To cite this version:}

Siegfried Rouvrais, Vanea Chiprianov. Architecting the CDIO Educational Framework Pursuant to Constructive Alignment Principles. International Journal of Quality Assurance in Engineering and Technology Education (IJQAETE), 2012, 2 (2), pp.80 - 92. 10.4018/ijqaete.2012040108 . hal00701142

\section{HAL Id: hal-00701142 \\ https://hal.science/hal-00701142}

Submitted on 27 May 2021

HAL is a multi-disciplinary open access archive for the deposit and dissemination of scientific research documents, whether they are published or not. The documents may come from teaching and research institutions in France or abroad, or from public or private research centers.
L'archive ouverte pluridisciplinaire HAL, est destinée au dépôt et à la diffusion de documents scientifiques de niveau recherche, publiés ou non, émanant des établissements d'enseignement et de recherche français ou étrangers, des laboratoires publics ou privés. 


\title{
Architecting the CDIO Educational Framework Pursuant to Constructive Alignment Principles
}

\author{
Siegfried Rouvrais and Vanea Chiprianov \\ Institut Telecom, Telecom Bretagne, Université Européenne de Bretagne, France
}

\begin{abstract}
On the one hand, no one international model for quality assurance evaluation of higher education has emerged. On the other hand, as a reference model rather than a prescription, the CDIO initiative proposes a mature integrated framework for creation or continuous improvement of engineering programs. However, institutions developing and managing educational programs have to juggle the expectation of various accreditation and evaluation bodies, which may create consistency and interoperability problems. There is an obvious need to unambiguously specify relations among quality assurance concepts in order to enable more transparent and comparable descriptions of quality frameworks for educational programs. Following constructive alignment principles, this article creates structural models using some of the CDIO Standards. In doing so it lays the foundations of an architectural meta-model for describing complex educational systems, which will contribute to consistency and interoperability among quality frameworks.
\end{abstract}

Keywords: Education, engineering, educational frameworks, CDIO, system thinking, design, models, quality assurance, constructive alignment, curriculum.

\section{INTRODUCTION}

The ongoing process of program transformation impacts an institution's operating modes, its quality and its future performance. The management of educational transformation is thus of strategic importance to universities, schools and programs. During the last decade, various models of quality management have emerged in the form of quality assurance (QA) criteria and standards that can help program leaders to evaluate and improve their various educational systems including curricula, workforce, workspaces, support services, and administrative processes. However, these complex QA frameworks are not always clearly described. As a result, the increasing complexity of their concerns, criteria, and standards requires new and different types of expertise on behalf of program designers and managers.

It is very difficult for educational organizations and their managers to ensure interoperability among existing QA programs and frameworks since no global unified model for higher education QA has yet emerged. Therefore, it is essential to identify the common core concepts of the various QA frameworks to facilitate the process of program design and transformation. A system modeling approach is an obvious choice for meeting such a challenge since it makes it possible to meaningfully, unambiguously, and accurately specify concepts, relations, and viewpoints among stakeholders. 
An educational program rest on three main pillars: 1) an intended or declared curriculum, 2) a enacted or taught curriculum, and 3) a validated or learned curriculum that share a set of common core concepts in the form of learning outcomes (Harden, 2001). The main objective of this article is to provide a framework for describing the concepts associated with these three pillars. This article identifies key concepts for modeling these pillars of educational programs following constructive alignment principles (Biggs, 1996). It is hoped that this effort will result in the unambiguous description of the relationships among these several concepts.

This article is structured as follows. As background, some existing notions of educational modeling are quickly surveyed. Next, three conceptual and structural models, that correspond to the aforementioned educational program pillars and support constructive alignment, are proposed based on three of the Conceive-Design-Implement-Operate (CDIO) Standards (CDIO, 2010). In this section it is argued that the other CDIO Standards can be regarded as resources, properties or constraints in such models. Relations between concepts of these models are then derived. The following section examines the benefits of educational system modeling for various stakeholders, and presents the requirements for constructing viewpoints that represent their concerns. This section then reviews some quality management models in education so as to pave the way for future work on architecting educational systems. The last two sections respectively provide some future directions and conclude this article.

\section{BACKGROUND: TOWARDS MODELING EDUCATIONAL FRAMEWORKS}

Analyzing an educational program from conceptual and structural perspectives reveals semantic relations among the three pillars, that are the intended or declared, the enacted or taught, and the validated or learned curricula (Harden, 2001). These three pillars share a set of common core concepts, principally in the form of learning outcomes. By analyzing the CDIO Standards from such perspectives it is possible to clarify and structure, at an abstract level, the currently complex CDIO standards. In fact, as the size and complexity of educational systems increase, it is a major challenge to unambiguously describe common concepts among the various stakeholders involved in program design or transformation. In such a context, modelling approaches allow one to represent, visualize, and document the artefacts of a system in terms of these different points of view. Models permit one to unambiguously and consistently describe concepts and their relationships (Muller et al, 2010). In addition, by minimizing ambiguities and introducing a certain degree of formality, modelling approaches enhance better understanding, coherency, alignment, analysis and (re)usability of common concepts, principles and recommendations related to program design or transformation.

\section{Managing Flexibility and Interoperability in Educational Frameworks}

The twelve CDIO Standards offer many keys for reforming and/or continuously improving engineering programs for preparing the next generation of engineers (Crawley et al, 2007). Representing much more than a simple syllabus that organizes learning outcomes, the CDIO Standards form a multidimensional educational constellation addressing several stakeholders' issues through recommendations regarding workspaces, curriculum integration, learning styles, faculty development, assessment, evaluation, and QA continuous improvement (CDIO, 2010).

In order to keep pace with the rapid evolution of societal environments and educational missions, first, the CDIO approach embodied in the Standards must remain dynamic by being 
continually updated. This is evident, for example, in recent changes of to CDIO Standard 2 syllabus items relating to sustainability, leadership and entrepreneurship issues (Crawley et al, 2011). Second, educational programs and institutions must adapt the CDIO framework to their own reality depending on quality requirements, that is, criteria defined by various professional or governmental accreditation boards as well as those specified in local quality management models. Third, educational programs and institutions are being expected to collaborate more extensively and more formally with a variety of internal and external partners to enhance their visibility, improve their ratings and rankings, and increase student exchanges. This is occurring within a context of increasing funding constraints. As a result, educational institutions must work within various educational and business systems and their related QA frameworks (Castelli et al, 2010).

These demands make flexibility and interoperability a major challenge. A systems thinking approach along with the CDIO Standards can help educational programs and institutions respond to these expectations and constraints. Taking its inspiration from a standard complex system architecting approach, this article lays the foundation for an architectural meta-model by highlighting concepts and properties of educational systems and holistically addressing the issues of interoperability and flexibility among educational QA frameworks.

\section{Educational Modeling, towards a System Thinking Approach}

In the context of system thinking, a model is defined as a "representation of the reality for a given purpose; it is an abstraction of reality in the sense that it cannot represent all aspects of reality, allowing people to deal with the world in a simplified manner, avoiding the complexity, danger and irreversibility of reality" (Rothenberg, 1989). Models can provide a means of integrating, clarifying, and making comparable, concepts inherent in various educational systems. Several relevant educational modeling languages exist for this purpose. Martinez-Ortiz et al (2007) classify education modeling languages in three categories:

1. Content Structuring Languages allow designers to arrange the learning resources in sequences, always taking into account the learner's needs and performance in order to improve the learning experience;

2. Activity Languages focus on the activities in general during the learning process; and

3. Evaluation Languages allow designers to describe the stages of the learning process in which problem-solving or question-answering are involved.

While initially developed for software engineering purposes, the Unified Modeling Language (UML) (Booch et al, 2005) is the accepted de facto standard for specifying and documenting software systems. Due to its significant expressiveness and relative simplicity, it is being used more and more to create visual models for other types of systems such as engineering systems, information or enterprise systems, and business and finance systems. Therefore, it is also a very good candidate for educational system and QA framework modeling.

UML uses several types of diagram components (notations) to visually represent structural modeling elements and to describe their relationships and interdependencies. Many types of relations can be captured. Three special types of relations, frequently used and therefore singled out in UML, are one-to-one association, containment and inheritance. Figure 1 shows the basic notations proposed in a specific UML diagram that are used in this article: 
1. The first Association relation, represented by a link, means there is a connection between two concepts. For example, the top relation in Figure 1 shows a one-to-one relationship between these two Concepts, where one AConcept that is associated with one AnotherConcept. An annotation or verb can be added to the link that describes the relationship.

2. Associations can also support multiplicities. This is shown by an $*$ on one end or on each end of a link. For example, the second relation of Figure 1 specifies that a

ContainingConcept is associated with zero or more ContainedConcepts (' $*$ ' multiplicity). By default, if there is no multiplicity specified on a link, then it is considered 1 (as in the first relation). Multiplicities can also be of type 1..*, if at least one ContainedConcept is required;

3. The third and last relation in the Figure 1, Inheritance, means that a SubConcept has all the properties of a SuperConcept (much like a child inherits all the belongings of his/her parent). SubConcept can have new properties that SuperConcept did not have, and can redefine properties inherited from SuperConcept. Note that the direction of the arrowed link is of importance.
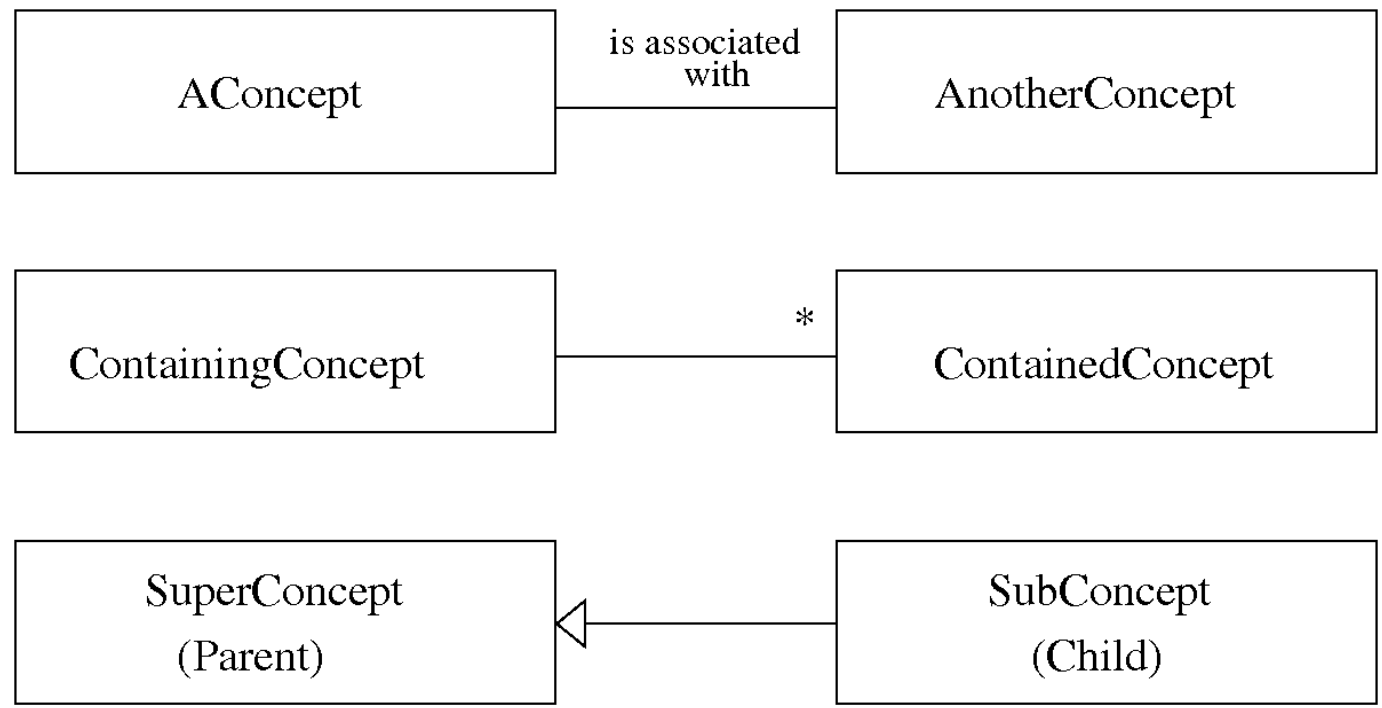

Figure 1. Basic relations between concepts for structural modeling in UML.

Apart from structural diagrams as presented, behavioral diagrams make it possible to capture the varieties of interactions among concepts, their inputs or outputs, and their current states and dynamic changes over time. To model these aspects, UML employs for example use case diagrams and communication diagrams. Temporal models could have been introduced using UML activity diagrams or by using other dedicated business process modeling notations (zur Muehlen et al, 2010). In fact, educational processes like student recruitment, pedagogical development and deployment, and course or project unit design and implementation require specific behavioral notations (Rouvrais et al, 2010). However, only structural views associated with conceptual information models will be considered in the remainder of this article. 


\section{STRUCTURALLY MODELING AN EDUCATIONAL FRAMEWORK: THE CDIO CASE}

The CDIO approach celebrated its 10th anniversary in 2011 and today provides a mature integrated framework for creating, reforming, or continuously improving engineering educational programs. Three of its Standards (2 Syllabus, 3 Integrated Curriculum and 11 Skills Assessment) are the cornerstone for constructive alignment (Malmqvist et al, 2011). As defined by Biggs (1996), constructive alignment clarifies the design of a curriculum and sheds light on the relationships among intended learning outcomes, teaching and learning activities, and the assessment of learning outcomes. As noted earlier Harden (2001) asserts that a curriculum is not limited to its current manifestation but can be separated into 1) an intended or declared curriculum, 2) an enacted or taught curriculum, and 3) a validated or learned curriculum. These three pillars share concepts in the form of the constructive alignment elements of learning outcomes, teaching and learning activities, and assessment methods. The main issue is the extent to which the elements of the constructive alignment model are the same or different in all three curricula.

When numerous curricular concepts are interconnected from both structural and behavioral perspectives, constructing an integrated curriculum can facilitate coherency, transparency, comparability among the concepts (Froyd \& Ohland, 2005). The following subsections discuss structural diagrams related to the three CDIO Standards that are relevant to an integrated curriculum as embodied in the constructive alignment model and the three manifestations of a curriculum. These diagrams highlight the conceptual information that describes the relationships among the three Standards (2 Syllabus, 3 Integrated Curriculum and 11 Skills Assessment). The diagrams can serve as case studies and as such provide heuristic devises applicable to clarifying the relationship of elements in other educational frameworks.

\section{Modeling Syllabus and Learning Outcomes}

The learning outcomes of a syllabus are one element of the intended or declared curriculum and one aspect of an integrated curriculum as viewed from a constructive alignment perspective. As is the case with CDIO Standard 2 Syllabus, these learning outcomes rarely occur in isolation. The related concepts and associations of the intended or declared curriculum can be represented in a diagram as in Figure 2, where a Syllabus is composed of zero or more Learning Outcomes (symbolized by an * that indicates multiplicity between the two concepts). Similarly, a learning outcome could be associated with zero or more Core Knowledge, Skills, or Activity Domains. Depending on the design rationale and educational framework, Core Knowledge and Skill are associated with Learning Outcome to derive particular core knowledge-oriented learning outcomes and skill-oriented learning outcomes. By inheritance, Skills can be of type Interpersonal or Personal such as the personal and professional skills and attitudes in the CDIO Syllabus (Crawley et al, 2011). These relationships are shown in the diagram through their direct association with the Learning Outcome element.

In addition, by inheritance, a learning outcome can be of type Optional (e.g. sustainability, leadership and entrepreneurship issues of the revised CDIO Syllabus (Crawley et al, 2011)). A learning outcome can also be associated with one or more Category $\left(1 . .^{*}\right)$. A category may include learning outcomes specificities as those embodied in Bloom's cognitive domain (Bloom et al, 1956) or Krathwohl's affective domain (Krathwohl et al, 1964). 
At the bottom level of the diagram are several Activity Domains, namely, Operating, Implementing, Designing, and Conceiving. These are associated with Syllabus through their Inheritance relationship with the Activity Domain (as sub-concepts) with Learning Outcomes. This implies that Learning Outcomes of all types will be influenced by the Activity Domain(s) with which they are possibly associated. Any program that has a Syllabus as its base can be described and evaluated for completeness or validity using a specific model such as the CDIO Syllabus or EUR-ACE European Qualifications Framework (EQF, 2008) as described by (Castelli et al, 2010).

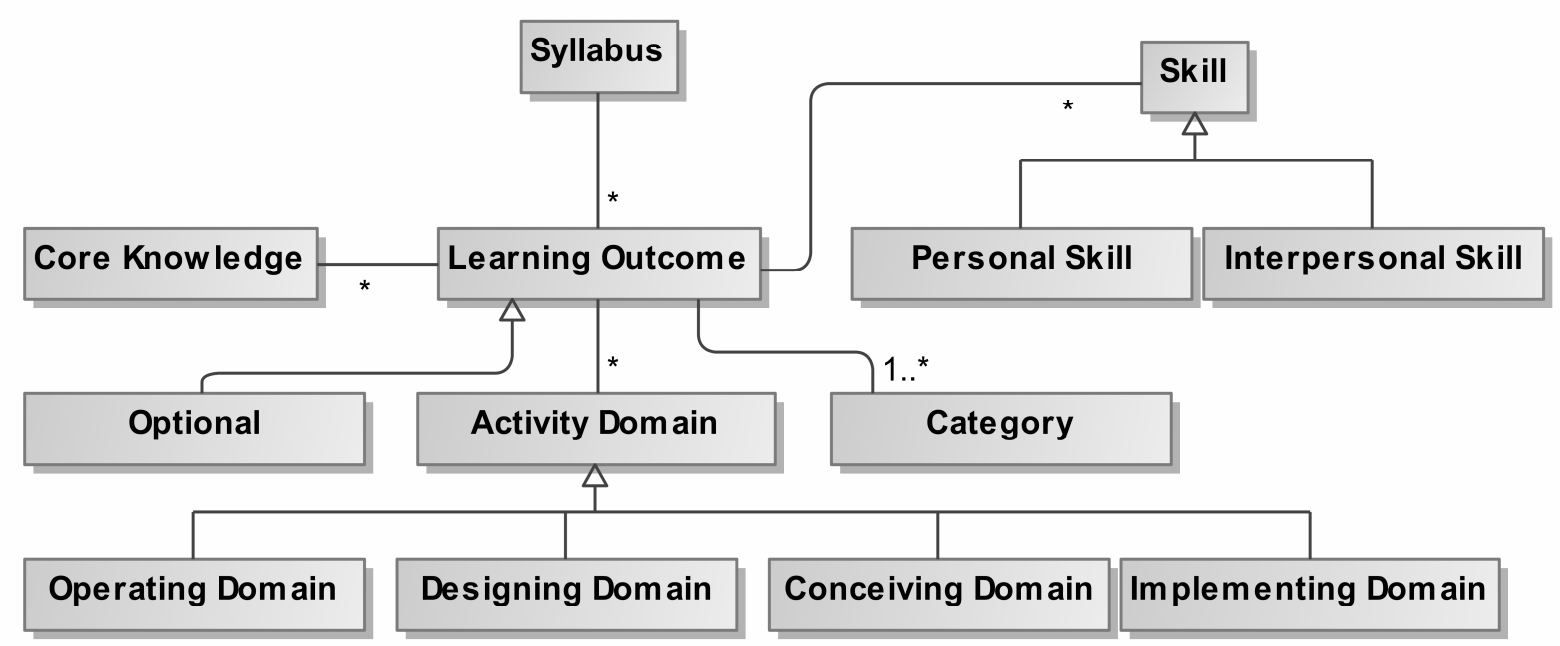

Figure 2. Syllabus Intended curriculum diagram.

\section{Modeling the Integrated Curriculum}

The second pillar of a program is the enacted or taught curriculum that is represented by the actual courses and associated elements of a particular program of study. In CDIO Standard 3 Integrated Curriculum, a CDIO compliant curriculum is described being designed with mutually supporting disciplinary courses and with an explicit plan to integrate personal and interpersonal skills, along with product, process, and system building skills. In addition, the CDIO Standards identify an Introduction to Engineering course that provides the framework for engineering practice (Standard 4), Design-Implement Experiences at a basic and advanced levels (Standard 5), and Integrated Learning Experiences (Standard 7) as part of a CDIO compliant program (CDIO, 2010).

It is possible to represent such elements of a program in a structural model like that shown in Figure 3. As represented in this figure a Program may contain one or more courses $\left(1 .{ }^{*}\right)$ and associated elements, for example, zero or more Extracurricular Activities $\left(0 . .^{*}\right)$ and multiple Internships (*). The Course concept is inherited by different types of courses such as Core, Introductory, Major, Minor, or Elective. A Course, whatever type, could contain multiple (*) Activities such as Tutorial, Laboratory, Lecture, Project, etc. These different types of activities can be combined conceptually in a Course to create, for example, a specific Project concept such as an Introductory Project or Major Capstone Project. As a result, Activity may consist of Active 
Learning approaches that are described in CDIO Standard 8 as teaching and learning based on active experiential learning methods. In addition, an Activity has Resources allocated to it. Resources can be for example a type of Room, that is, facilities in the form of engineering workspaces and laboratories that support and encourage hands-on learning (CDIO Standard 7), and Teacher or other instructional staff with various roles, responsibilities and competencies as embodied in CDIO Standards 9 and 10.

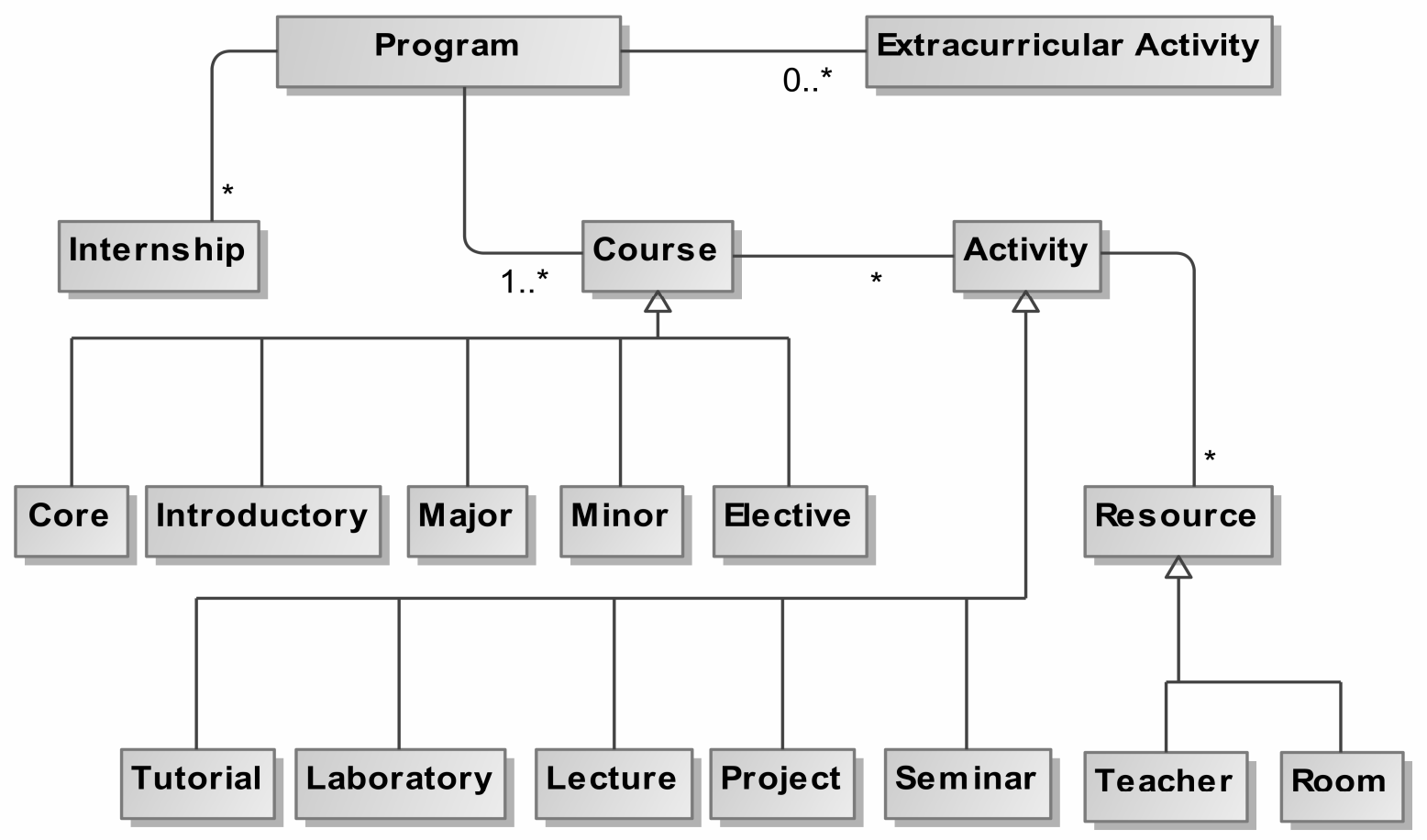

Figure 3. Taught curriculum diagram.

\section{Modelling Skills Assessment}

The third pillar of a program, the validated or learned curriculum is based on various types of student learning assessment activities (Boud, 2010). These activities are the focus of CDIO Standard 11 Learning Assessment (CDIO, 2010). Assessment concepts and associations can be represented in a diagram such as that in Figure 4. The Assessment concept is of different types, e.g. as the following methods proposed by inheritance: Portfolio, Interview, Report, Exam, Moral Assessment, or Oral Presentation. There may be one or more Forms of Assessment organized under the Formative or Informative sub-concepts, often termed summative assessment. In addition, Assessment is typically associated on a 1-* basis with Proficiency Levels used to validate the accomplishment of student learning, in other words, the learned curriculum.

The customized CDIO Syllabus described in Crawley (2001) indicates expected interim and final levels of proficiency (in parentheses, e.g. 4.4/4) relative to the leaning outcomes. These expected levels of proficiency were obtained by surveying key stakeholders among the alumni, faculty, and industry. In addition, this customized syllabus has outcomes that are stated in 
behavioral terms that facilitate either the Formative or Informative Form of assessment (Crawley, 2001, p C-1):

\section{PERSONAL AND PROFESSIONAL SKILLS AND ATTRIBUTES}

\subsection{ENGINEERING REASONING AND PROBLEM SOLVING (4.0)}

2.1.1 Problem Identification and Formulation (4.4/4)

Evaluate data and symptoms

Analyze assumptions and sources of bias

Demonstrate issue prioritization in context of overall goals

Formulate a plan of attack (incorporating model, analytical and numerical solutions

Qualitative analysis, experimentation and consideration of uncertainty

Proficiency level also could be measured using the European Qualification Framework (EQF, 2008) that includes eight levels of proficiency described in terms of learning outcomes. And Bloom's (Bloom et al, 1956) or Krathwohl's (Krathwohl et al, 1964) taxonomies could be used to categorize proficiency levels.

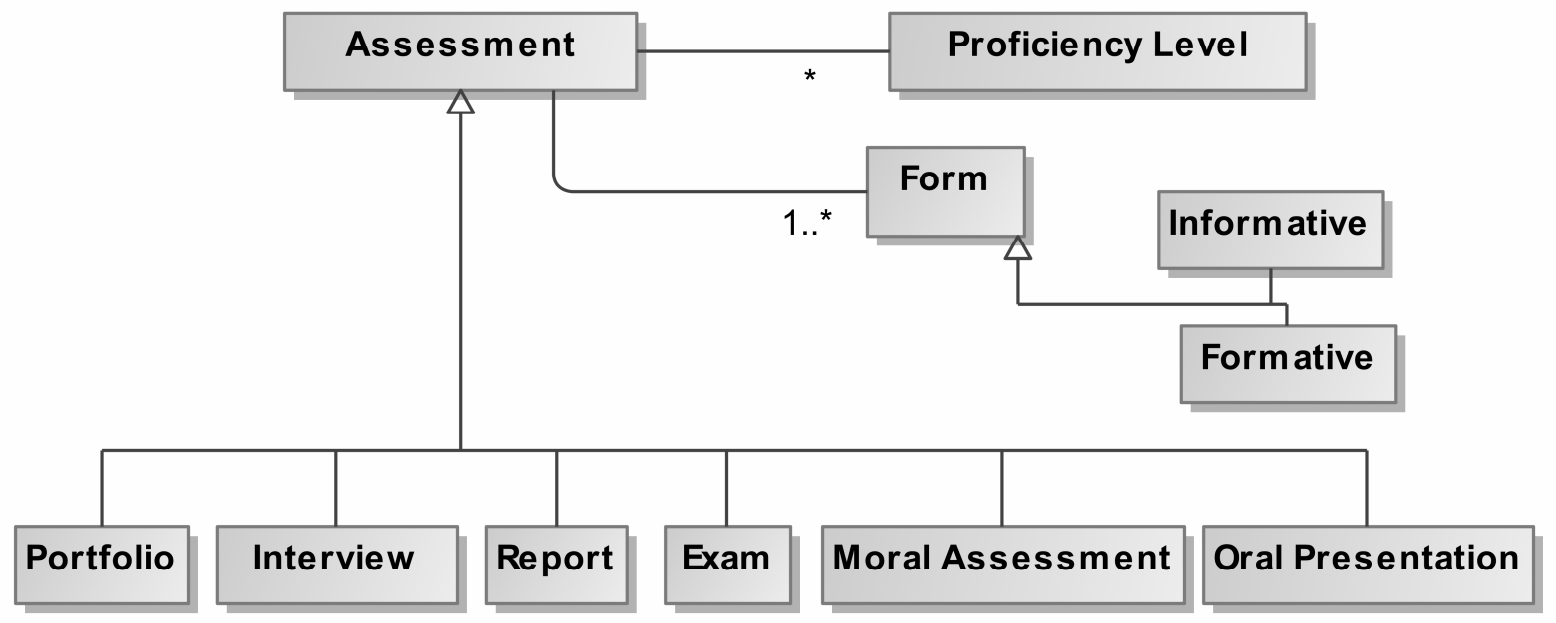

Figure 4. Validated curriculum diagram.

\section{Other CDIO Standards}

We propose three diagrams that focus on nearly all of the CDIO Standards as a graphical representation of the three curriculum pillars. However, a conceptual information model also contains elements of documentation and judgment that are embodied in CDIO Standard 12 Program Evaluation. Since this concept is quite overarching, it could be viewed as a behavioral activity supporting continuous improvement based on the lessons learned relative to the various CDIO Standards when comparing and contrasting the intended or declared curriculum, the enacted or taught curriculum, and the validated or learned curriculum. CDIO Standard 1 CDIO The Context, can be seen as representing the principles to follow or a mission statement and as such will be discussed in the following section on architecting educational frameworks.

\section{Relationships among Conceptual Information Models}


Following constructive alignment principles, the connection between the first intended or declared curriculum (Figure 2) and the third validated or learned curriculum (Figure 4) lies in the fact that the Assessment concept in Figure 4 is associated with the Proficiency Level that a student has achieved for a Learning Outcome as shown in Figure 2. This relation is depicted at the bottom/left of Figure 5, with a one or more multiplicity $\left(1 . .^{*}\right)$ on both ends.

Learning outcomes are also multiply associated with Activities of the enacted or taught model as shown in Figure 5 (1..*). As simple two dimensional matrixes, curriculum maps are used to visually represent the association between learning outcomes and activities embodied in intended and taught curriculum (Harden, 2001). Curriculum mapping facilitates transparency among stakeholders and facilitates completeness and coherency of learning outcomes in the intended and declared curriculum. Proficiency or degree level expectations can be introduced at the intersection in such matrixes when a course addresses a specific learning outcome and can be based on a variety of schemes (EQF, 2008; Bloom et al, 1956; Krathwohl et al, 1964; Crawley, 2001).

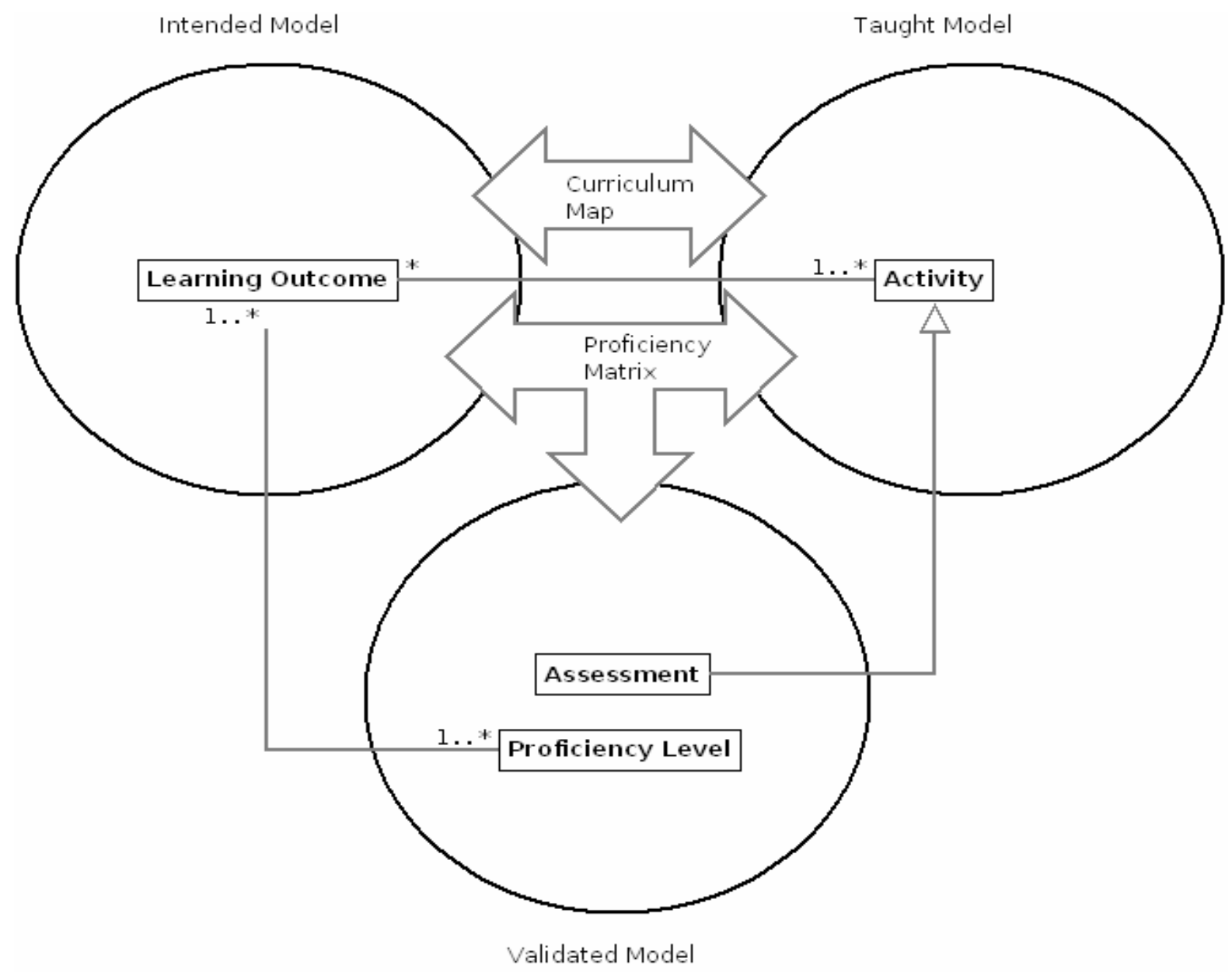

Figure 5. Concept associations among conceptual information models. 


\section{ARCHITECTING AN EDUCATIONAL SYSTEM INCORPORATING STAKEHOLDER VIEWPOINTS}

Following an architectural modeling approach is the key to understanding and managing complex educational systems. As stated in recommended practice IEEE 1471 (IEEE, 2000), a system is best documented via its architecture. As such, an educational system can be described through a set of architectural models that consists of the concepts and properties of its constituent sub-systems. It exists within a particular environment and fulfills one or several missions, as expressed in the CDIO Standard 1 The Context, for example.

In architecting an educational system it is possible to evolve a detailed description of the system while taking into account stakeholder views as shown in Figure 6. Following the path on the left side of the figure an Educational System has one Stakeholder or more (1..*), for example, the alumni, faculty, and industry people who provided input on the desired proficiency level of the CDIO Syllabus topics (Crawley, 2001). Each Stakeholder has one or more (1..*) Concerns (e.g. reputation, ranking, quality of education, valuable professionals) that covers one Viewpoint or more (1..*), e.g. financial, technical support, resource management viewpoints. Each Viewpoint then conforms to a particular View.

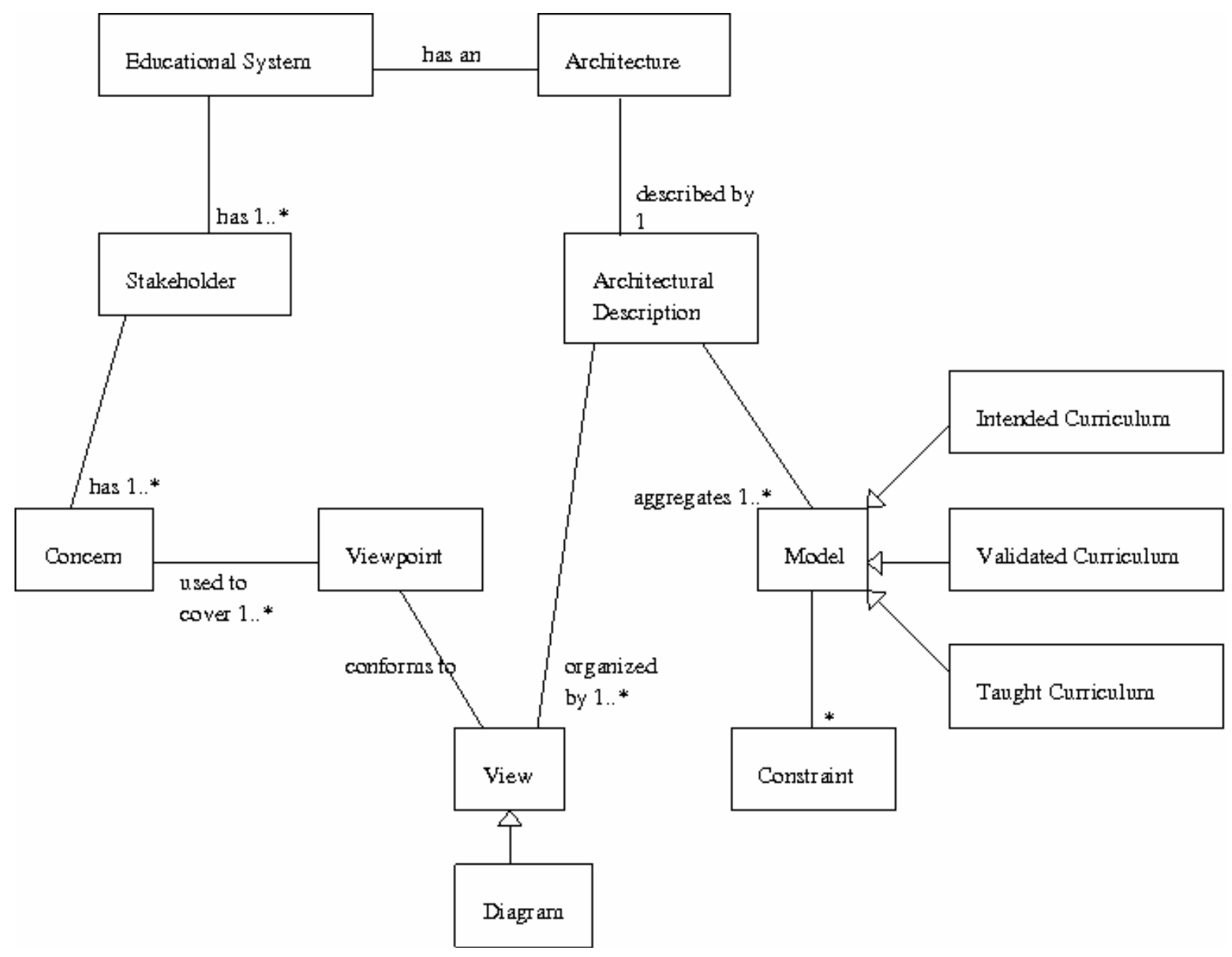

Figure 6. IEEE-1471 system overview meta-model applied to educational systems. 
Following the path on the right side of the figure an Educational System has an Architecture that is delineated by a unique and, ideally, unambiguous Architectural Description. Fundamentally, the Architectural Description is organized by one or more Views (1..*), related to Stakeholder Viewpoints. A type of views is Diagram, which permit to visualize concepts specific to education and relation between them. The Architectural Description aggregates one or more (1..*) Models such as the three pillars of a curriculum. Models may be bounded by a multitude of Constraints (*) such as those inherent to the CDIO Standards or EUR-ACE European Qualifications Framework. Models are independent of Diagrams, because they can be described both graphically (using diagrams) and textually.

Educational system design and transformation involves many stakeholders. The approach described makes it possible to unify multiple stakeholder views through architectural modeling. By constructing an educational system architecture the aggregation of multiple conceptual information models and their specific properties and constraints can be accomplished thus making it easier to understand the relations among shared concepts and, as a result, minimize ambiguities. Aggregating multiple conceptual information models allows educational planners and managers to address issues related to coherency and consistency early in the conceiving and designing phases, which can keep such issues from proliferating during the implementation and operational phases of educational system design and transformation.

\section{Benefits for QA}

Higher education institutions and programs are more and more required by professional societies and/or governmental agencies to meet quality standards (Patil \& Gray, 2010). In order to do so, it is often said that two distinct disciplines must be mastered: engineering and management. QA frameworks and requirements defined by accreditation bodies (e.g. ABET, EUR-ACE, Engineers Australia) often incorporate quality management processes in their standards. The CDIO Standards have associated customized rubrics that provide guidance for self-evaluation and QA (CDIO, 2011) (See Gray elsewhere in this issue.) In particular, Standard 12 Program Evaluation is CDIO's cornerstone of QA and continuous improvement. As such, the CDIO self-evaluation formative approach to QA is a complement to the other more formal frameworks and requirements. (See Malmqvist, Brennan, Costa and Sellens elsewhere in this issue).

Quality management processes are critical for systematic and continuous improvement. This is exemplified by the highest levels of CDIO compliance (CDIO, 2011, p 2):

- Level 5: Evidence related to the standard is regularly reviewed and used to make improvements.

- Level 4: There is documented evidence of the full implementation and impact of the standard across program components and constituents.

Level 5 in particular suggests evaluation by groups external to the program. The kinds of structural and process models described in this article have great potential for ensuring regular systematic review of engineering programs, as well as their continuous improvement.

The architecting diagrams in this article can provide heuristic devises applicable to clarifying the relationship of elements in other educational frameworks related to continuous improvement and QA. A systems thinking approach along with the CDIO Standards can help educational programs and institutions respond to these expectations. In addition, introducing a certain degree 
of formality and thus minimizing ambiguities, modelling approaches enhance better understanding, coherency, alignment, analysis and (re)usability of common concepts, principles and recommendations related to program design or transformation.

Another benefit of modeling educational systems using an architectural perspective is that it is possible to address issues related to interoperability among different QA standards or requirements at a meta-model or framework level. Addressing issues related to coherency and consistency among different QA approaches can facilitate co-operation among institutions using different standards or requirements. For example, if the relations between concepts from the CDIO standard and e.g. concepts from the EUR-ACE standard are described through a metamodel, then the relations between models can be clarified and validated for all instances which conform to these models. It is therefore sufficient to describe the relations between models only once. They then can be systematically applied to specific instances such as a particular institution or program.

\section{FUTURE DIRECTIONS}

In this article, we mainly focused on the structural and informational modeling aspects using a Unified Modeling Language (UML)-like notation. UML is a comprehensive set of graphic notations and thus permits the representation and visualization of a system structure, its behavioral activities, processes, and actors, and the relationships among them. Such a modeling language offers the advantage of a unified language, capable of describing a wide range of domains that can be more easily understood by all stakeholders. While this is very useful from a conceptual, informational and structural perspective, more details are often needed to deeply describe a system. The simple structural modeling notations used in this article lack the semantic strength required to represent such wider details.

To address this deficit it is proposed that Educational Architecture modeling includes Domain Specific modeling language to be used at more detailed levels (Khoury, 2007). Domain specific modeling languages allow experts to express, validate and modify solutions, and achieve tasks specific to their domain, in this case QA in educational systems. Domain specific modeling languages require less cognitive design expertise than a more general purpose language such as UML (Green and Petre, 1996). As domain experts know much better their domain, the models they produce have an enhanced quality, productivity, reliability, maintainability, and reusability.

We propose as future work to design dedicated and, it is hoped, more easily understandable graphical languages to facilitate modeling of educational system design and transformation by non-UML experts. To realize these advantages, the diagrams in Figures 2, 3, and 4 will need to be validated by educational designers so as to make them valuable for future Educational Architecture modeling. Developing appropriate Domain Specific modeling language notations and abstractions will make it possible to visualize, specify, construct and document an educational system QA meta-model or framework that is easily understood by the higher education community.

\section{CONCLUSION}

Educational frameworks are defined with varying degrees of rigor, and can thus lead to ambiguities among stakeholders having different concerns. To date, there is no standard commonly accepted way of conceptually describing educational systems, especially those related 
to continuous improvement and QA. To address this lack and to enable more transparent and comparable descriptions, this article shows how architecting methods can be employed to provide high-level descriptions of educational systems. Based on constructive alignment principles, it proposes conceptual information models for capturing and exchanging concepts and data from the intended or declared curriculum, enacted or taught curriculum, and validated or learned curriculum.

By identifying common concepts and building blocks as represented in the CDIO framework, the three proposed structural graphical models presented in this article allow us to describe and represent engineering education curricula more abstractly, so as to minimize ambiguities among stakeholders and sustain flexibility in design and transformation processes. As such, the proposed conceptual information models contribute to improving the portability and interoperability among existing programs and reference QA standards and frameworks, as well as facilitating continuous improvement in a QA context.

\section{REFERENCES}

Biggs, J. (1996). Enhancing Teaching through Constructive Alignment. Higher Education, 32, 347-363.

Bloom, B.S., Englehart, M. D., Furst, E. J., Hill, W. H., \& Krathwohl, D. R. (1956). Taxonomy of Educational Objectives: Handbook I-Cognitive Domain. New York: McKay.

Booch, G., Rumbaugh, J., \& Jacobson, I. (2005). Unified Modeling Language User Guide. The Addison-Wesley Object Technology Series. Reading, MA, USA: Addison-Wesley Professional.

Boud, D. (2010). Assessment 2020: Seven Propositions for Assessment Reform in Higher Education. Australian Learning and Teaching Council.

Castelli, A., Marinoni, C., Bisagni, C., Brodeur, D. R., Crawley, E. F., Causi, A., Fortin, C., Malmqvist, J., \& Maury, C. (2010). An Integrated CDIO-EQF Engineering Framework for Europe. Paper presented at the 6th Intl. CDIO Conference, École Polytechnique, Montréal.

CDIO (2010). The CDIO Standards v 2.0 (with customized rubrics). Retrieved November 14, 2011 from http://www.cdio.org/knowledge-library/documents/cdio-standards-v-20-customizedrubrics

\section{CDIO (2011) (See Gray elsewhere in this issue.)}

Crawley, E. F. (2001). The CDIO Syllabus: A statement of goals for undergraduate engineering education. Retrieved November 17, 2011 from http://www.cdio.org/framework-benefits/cdiosyllabus-report

Crawley, E. F., Malmqvist, J., Brodeur, D. R., \& Östlund, S. (2007). Rethinking Engineering Education - The CDIO Approach. New York: Springer-Verlag. 
Crawley, E. F., Malmqvist, J., Lucas, W. A., \& Brodeur, D. R. (2011). The CDIO Syllabus v2.0 : An undated statement of goals for engineering education. Retrieved November 17, 2011 from http://www.cdio.org/framework-benefits/cdio-syllabus

EQF (2008). The European Qualifications Framework. European Commission, Education \& Training. Retrieved September 27, 2011, from

http://ec.europa.eu/education/lifelong-learning-policy/doc44_en.htm

Froyd, J. E., \& Ohland, M. W. (2005). Integrated Engineering Curricula. Journal of Engineering Education, 94(1), 147-164.

Green, T., \& Petre, M. (1996). Usability Analysis of Visual Programming Environments: A 'Cognitive Dimensions' Framework. Journal of Visual Languages and Computing, 7(2), 131174.

Harden, R. M. (2001). Curriculum Mapping: A Tool for Transparent and Authentic Teaching and Learning. AMEE Guide No. 21. Medical Teacher Journal of the Association for Medical Education in Europe, 23(2), 123-137.

IEEE (2000). Recommended Practice for Architectural Description of Software-Intensive Systems. Institute of Electrical and Electronics Engineers, IEEE Standard No 1471.

Khoury, C. R. (2007). A Unified Approach to Enterprise Architecture Modelling. PhD thesis, University of Technology, Sydney.

Krathwohl, D.R., Bloom, B.S., \& Masia, B.B. (1964). Taxonomy of educational objectives: Handbook II: Affective domain. New York: David McKay Co

Malmqvist, Brennan, Costa and Sellens (2012). (elsewhere in this issue)

Malmqvist, J., Knutson Wedel, M., \& Enelund, M. (2011, June). Constructive Alignment for Degree Projects Intented Learning Outcomes, Teaching and Assessment. Paper presented at the 7th Intl. CDIO Conference, Technical University of Denmark, Copenhagen.

Martinez-Ortiz, I., Moreno-Ger, P., Sierra, J. L., \& Femandez-Manjon, B. (2007). Educational Modeling Languages - A Conceptual Introduction and a High-level Classification. Computers and Education: E-Learning, From Theory to Practice. Springer, 27-40.

zur Muehlen, M., Wisnosky, D. E., \& Kindrick, J. (2010). Primitives: Design Guidelines and Architecture for BPMN Models. In M. Rosemann, P. Green, \& F. Rohde (Eds), $21^{\text {st }}$ Australasian Conference on Information Systems. AIS Electronic Library.

Muller, P-A., Fondement, F., Baudry, B., \& Combemale, B. (2010). Modeling Modeling Modeling. Software and Systems Modeling Journal, 4(9), 943-958. 
Patil, A.S., \& Gray, P. J. (Eds.) (2009). Engineering Education Quality Assurance: A Global Perspective. Springer.

Rouvrais, S., Mallet, J., \& Vinouze, B. (2010, October). A Starter Activity Design Process to Deepen Students Understanding of Outcome-related Project Learning Objectives. Paper presented at the 40th ASEE/IEEE Frontiers in Education Conference, Arlington, Washington D.C.

Rothenberg, J. (1989). The Nature of Modeling. In L.E. William, K.A. Loparo \& N.R. Nelson, (Eds), Artificial Intelligence, Simulation, and Modeling. New York, John Wiley and Sons, Inc. 75-92. 